\title{
APRESENTAÇÃO: LINGUÍSTICA SISTÊMICO-FUNCIONAL
}

Lucia Rottava (UFRGS)

luciarottava@gmail.com

Cristiane Fuzer (UFSM)

cristiane.fuzer@ufsm.br

Karen Santorum (UFSM)

karensantorum13@gmail.com

"Na vida sempre fazemos escolhas, ainda que nossa escolha seja não escolher." Carmem Miranda (1909-1945), cantora, atriz e dançarina luso-brasileira

Com a frase em epígrafe, queremos destacar uma das palavras-chave da Linguística Sistêmico-Funcional (LSF), temática do presente número da revista Organon: "escolha". O poder de escolha é a base das sociedades democráticas, que prezam pela liberdade dos indivíduos e das coletividades de se expressar, de pensar e de existir. Dentre os vários âmbitos de escolhas em que os seres humanos podem atuar, as escolhas linguísticas podem ocasionar fortes impactos na vida social, ao mesmo tempo em que influenciam contextos e são por estes influenciadas.

Numa época em que os espaços para manifestações discursivas se ampliaram com a internet e as redes sociais, estudar as escolhas linguísticas e os significados que produzem nos contextos em que circulam é cada vez mais necessário na luta pela preservação do direito de escolhas na sociedade, balizadas pelo respeito, pela responsabilidade e pela ética.

Descrever, compreender e explicar o funcionamento da linguagem em suas diversas manifestações na vida social é uma das tarefas dos cientistas da linguagem que pensam e estudam os discursos sob a perspectiva da Linguística Sistêmico-Funcional, abordagem que se fundamenta na teoria léxico-gramatical de Michael Alexander Kirkwood Halliday (19252018), para quem a língua é uma rede de sistemas de significados em potencial. Nas palavras do linguista, "a língua é como é por conta das funções que desenvolveu para servir à vida das pessoas" (HALLIDAY, 1978, p. 4). 
Acolhendo ao convite das organizadoras do número 71 da revista Organon, do Instituto de Letras da Universidade Federal do Rio Grande do Sul (UFRGS), pesquisadoras e pesquisadores de diversas instituições do Brasil e da América Latina compartilham resultados de pesquisas que fomentam e possibilitam aprimorar metodologias de ensino e aprendizagem em diferentes níveis. Os 24 artigos, a Lista de Termos da LSF em português brasileiro e a resenha indicam as contribuições da LSF para a descrição e análise linguística e para os multiletramentos e o seu potencial de interlocução com outras abordagens teóricas.

A sequência dos artigos apresentados neste número da Organon foi agrupada em temáticas que contemplam diferentes dimensões que a LSF oferece: descrição e análise linguística (nove artigos), educação linguística (dez artigos), interlocuções teóricas (cinco artigos). O número temático encerra-se com uma Lista de Termos da LSF e uma resenha.

Os nove estudos de descrição e análise linguística, apresentados a seguir, focalizam realizações léxico-gramaticais e/ou semântico-discursivas dos significados em textos produzidos em contextos midiático, científico e educacional.

Com foco nos significados ideacionais experienciais, Fábio Alexandre Silva Bezerra (UFPB) e Anderson Alves de Souza (UFPB), no artigo "Jair Bolsonaro e a pandemia de COVID-19 nas capas da Carta Capital e da Veja: análise de transitividade de manchetes e lides”, apresentam uma análise de escolhas do sistema de transitividade que evidenciam representações (HALLIDAY; MATTHIESSEN, 2014) e, a partir dos resultados, discutem alinhamentos editoriais.

Também contemplando o sistema de transitividade, desta vez em narrativas autobiográficas que permitem inferir a construção da identidade de um professor de Língua Brasileira de Sinais, Thiago Lemes de Oliveira (UFU) e Tania Regina de Souza Romero (UFLA), no artigo " $\mathrm{Da}$ imersão à emersão: narrativa e transitividade na ressignificação do eu", refletem sobre influências socioculturais, experiências vivenciadas e circunstâncias adversas que foram impostas durante a constituição pessoal. A análise dos excertos, categorizados em Infância e Adolescência, mostra que a construção da identidade é inferida a partir da menção às pessoas (avó, mãe) mencionadas na autobiografia durante os momentos de trauma e ressignificação.

Com foco nos sistemas da Transitividade, de MODO e de Tema, Alex Bezerra Leitão (UnB) e Ruy Martins dos Santos Batista (UnB) trazem a sua contribuição para a LSF com o artigo "Neoliberalismo em resumos de artigos científicos no combate à Covid-19: um estudo sistêmico-funcional". Os resultados mostram, sob o olhar da transitividade, uma agenda governamental dinâmica e neoliberal, com o intuito de dar continuidade ao modelo capitalista 
de exploração. Do ponto de vista do sistema de MODO, a troca de informações é usada com o intuito de influenciar a audiência sobre a necessidade de políticas públicas para o aumento de práticas neoliberais, em virtude dos impactos econômicos causados pela pandemia. Em relação ao sistema de Tema, o predomínio do Tema Tópico, seguido do Tema Textual e do Tema Interpessoal, é usado para construir mensagens e organizar, de forma coerente, os significados experienciais e interpessoais nos resumos.

Situados no estrato semântico-discursivo, recursos do sistema de Avaliatividade (MARTIN; WHITE, 2005) são contemplados em três trabalhos. Carolina Zeferino Pires e Letícia Domanski, ambas doutorandas no Programa Pós-Graduação em Letras na UFRGS, no artigo "Engajamento sob o viés da linguística sistêmico-funcional em texto midiático: análise de um artigo de opinião de Miriam Leitão", abordam os recursos de posicionamento intersubjetivo com o objetivo de compreender como são construídas as relações entre a autora e o seu público leitor. A análise das ocorrências de engajamento em cada parágrafo do texto e, posteriormente, uma discussão mais detalhada nos dois últimos parágrafos, revelam que os movimentos — de alternância entre monoglossia e heteroglossia ao longo do texto — indicam alta responsabilidade autoral, no primeiro caso, e uma abertura de canal comunicativo, no segundo, sem comprometer tal responsabilidade.

Com foco no subsistema de gradação em corpus que permite olhares qualiquantitativos, Rodrigo Esteves de Lima-Lopes (Unicamp) e Carolina Palma de Sousa Arruda (Unicamp), no artigo "Estratégias de gradação em comentários de um vídeo no YouTube", analisam comentários extraídos de um vídeo no YouTube apoiando um candidato à presidência da república de extrema-direita. Utilizando a Linguística de Corpus para coleta e análise das ocorrências, os autores destacam como principal resultado o uso da palavra mito acompanhada por uma série de variações ortográficas, responsáveis por diferentes tipos de ênfase, especialmente na perspectiva da intensificação.

Para refletir sobre o ensino remoto de línguas na pandemia, Renato Caixeta da Silva (CEFET-MG) e Eliane Velloso Missagia (CEFET-MG) recorrem ao sistema de Avaliatividade, especificamente ao subsistema de atitude, no artigo "Avaliações docentes sobre o ensino remoto na pandemia à luz da Linguística Sistêmico-Funcional: recursos tecnológicos, materiais didáticos e avaliatividade em foco". Os resultados da análise das avaliações de atitude nos dizeres de 130 docentes de línguas em resposta a um questionário online indicam que o impacto do ensino remoto foi avaliado como um sentimento de insegurança e exaustão e que lidar com o letramento digital não tem sido uma tarefa simples, 
visto essa situação educacional ter requerido abrupta mudança, desvelando ainda mais desigualdade de acesso aos recursos tecnológicos e ao conhecimento.

Voltado para o contexto educacional de língua inglesa para crianças, o artigo "Um olhar da Avaliatividade para a construção de crenças de alunos sobre o professor de inglês", de Adriana Nogueira Accioly Nóbrega (PUC-Rio) e Mara Regina de Almeida Griffo (PUCRio), analisa recursos do subsistema de atitude e sua correlação com a construção das crenças de alunos sobre um "bom professor de inglês". Como resultados, as autoras destacam que as crenças "emergem de avaliações de afeto e de julgamento e relacionam-se à experiência do profissional, ao domínio do idioma e à importância do lúdico na formação do aluno".

$\mathrm{Na}$ linha das pesquisas que contemplam a multimodalidade aliada à descrição da língua com textos que circulam na mídia, o artigo de Karen Tank Mercuri (Unicamp), intitulado "Mídia na mira: julgamentos e discursos de ódio disseminados por hashtag no Twitter", apresenta uma análise de comentários no Twitter que acompanharam a hashtag \#FolhaPutinhaDoPT, em 2018, buscando entender o comportamento de parte da população em relação à imprensa. Recorrendo ao sistema de Avaliatividade e à Gramática do Design Visual, de Kress e van Leeuwen (2006), a autora depreende da análise três resultados principais: desmoralização de alguns meios de comunicação, sobretudo quando estes traziam notícias; ataque aos adversários políticos como mecanismo de defesa; campanha por propagação de hashtags de apoio, como estratégia para contrariar e tirar o foco da notícia da Folha de S. Paulo que expunha uma rede de espalhamento, por exemplo, de fake news.

A multimodalidade também é contemplada no estudo de Alex Caldas Simões (UNIFESP), com o artigo "Estrutura Potencial do Gênero (EPG) e multimodalidade: a configuração do gênero tira cômica seriada", com o objetivo de compreender a configuração dos gêneros multimodais em termos de sua Configuração Contextual e Estrutura Potencial do Gênero tira cômica seriada. Os resultados mostram que apenas os elementos obrigatórios (Formato Retangular, Cor, Estrutura Narrativa, Personagem, Espaço e Tempo, Assinatura Autoral, Identificação Bibliográfica, Seriação) foram encontrados, estando ausentes os elementos opcionais (Iterativos, Legenda, Balão, Linhas e Traços, Metáfora Visual, Sarjeta e Requadro).

As contribuições da LSF para a educação linguística em contextos escolar e acadêmico são contempladas em dez estudos, a seguir apresentados, que trazem reflexões e discussões decorrentes de análises de documentos oficiais para o ensino da linguagem e/ou de aplicações pedagógicas, bem como propostas metodológicas para processos de letramentos, envolvendo linguagem verbal e/ou multimodal. 
Focalizando a Base Nacional Comum Curricular (BNCC), documento que apresenta parâmetros para a educação básica brasileira, na área de Língua Portuguesa, Rosana Maria Schmitt (UFSM) e Francieli Matzenbacher Pinton (UFSM), no artigo "A BNCC e o ensino de Língua Portuguesa: em foco as habilidades do campo de atuação jornalístico-midiático", buscam compreender como são contemplados os objetos de conhecimento e os contextos de aprendizagem nas habilidades no Ensino Fundamental. Para essa compreensão, as autoras analisam as habilidades da BNCC do campo de atuação jornalístico-midiático a partir de uma pesquisa que denominam de documental e justificam a seleção de habilidades do campo por representar o maior número dentre as demais que o referido documento contempla. A descrição e a análise dos dados linguísticos que as autoras apresentam incluem a estrutura típica das habilidades e a figura do Sistema de Transitividade. Com base nessa análise, o artigo revela em que medida as habilidades desse campo dialogam com a perspectiva de ensino como gêneros textuais/discursivos proposta pela BNCC.

Tendo como pano de fundo também a BNCC e como aporte teórico a Pedagogia com base em Gêneros da Escola de Sydney (PGES), Heryzânya Alves Ramalho (IFRN), Orlando Vian Jr. (UNIFESP/CNPq) e Jennifer Sarah Cooper (UFRN), no artigo "Gêneros de texto na BNCC: um diálogo com a Pedagogia com base em Gêneros da Escola de Sydney”, delineiam as orientações relacionadas aos gêneros de texto em todas as etapas da educação (Infantil, Fundamental e Médio). Os autores destacam o uso da PGES associada à pedagogia crítica de Paulo Freire como suporte teórico-metodológico no trabalho com gêneros.

Tendo em vista aplicações da Pedagogia com base em Gêneros da Escola de Sydney, em contextos de ensino e aprendizagem no Brasil, Cristiane Fuzer (UFSM), Carla Carine Gerhardt (UFSM) e Orlando Vian Jr. (UNIFESP), no artigo "Abordagem de gênero da Escola de Sydney e seu uso no contexto educacional brasileiro: uma discussão terminológicoconceitual sobre estórias e histórias", propõem um debate sobre aspectos divergentes nas culturas a partir da reflexão sobre possibilidades de tradução dos termos story and history para, então, apresentar alternativas que poderiam dar conta das diferenças e atender às necessidades de professores brasileiros.

Considerando o contexto argentino, Estela Inés Moyano (UNGS/UNab/UFLO), em sua reflexão teórica no artigo "Metodología para la descripción de géneros en el marco de la Lingüística Sistémico-Funcional: su adaptación al español”, delineia uma proposta metodológica que parte da análise do texto para determinar a estrutura esquemática e os recursos semântico-discursivos de sua realização. Dentre os passos, destaca a preparação do texto para a análise, segmentando em orações, observando o registro e gerando hipóteses 
sobre o gênero e as etapas que o desenvolvem. O passo seguinte é a análise dos recursos linguísticos, dentre eles os recorrentes no sistema discursivo.

$\mathrm{Na}$ área de letramento acadêmico, Yanina Elisabeth García (UFLO) e Estela Inés Moyano (UNGS/UNab/UFLO), no artigo "El macrogénero escenarios: una experiencia de enzeñanza a lo largo del curriculum desde la Lingüística Sistémico-Funcional”, reportam a experiência de implementação de uma proposta didática para estudantes universitários no curso de Administração de empresas em uma universidade argentina. O ponto de partida da pesquisa é o Programa de Leitura e Escrita Acadêmica (PROLEA), desenvolvido pela segunda autora, com o objetivo de oferecer aos estudantes ferramentas para desenvolver as suas habilidades leitoras e as competências na escrita (MOYANO, 2018). Especial atenção é dada à noção de macrogênero, denominado pelas autoras de escenarios, ou seja, um texto que apresenta linguagem especializada e contribui para a realização de propósitos inerentes ao discurso na ciência e realizado mediantes abstrações, metáforas gramaticais nominalizações. (HALLIDAY; MARTIN, 1993; MARTIN; VEEL, 1998; MOYANO, 2013). Os dados analisados são os textos produzidos com base na proposta pedagógica implementada no PROLEA. A análise centra nos dados resultantes da elaboração da primeira versão do texto, seguida de sua versão final, contemplando os recursos linguísticos mais significativos do estrato semântico-discursivo. Os resultados denotam a contribuição de cada uma das etapas desenvolvidas na proposta com vista à apropriação do discurso científico, destacando-se o estudo do macrogênero em foco e sua intersecção entre a linguagem e a prática profissional.

A articulação entre a escrita científica e a abordagem de gêneros é o foco de Carolina Andrea Mirallas (UNSL - CONICET) no artigo "Assessment of a genre-based approach to scientific writing through the analysis of student-produced abstracts". A autora implementou um curso em inglês com base no programa de letramento Ler para Aprender (PLpA) (ROSE; MARTIN, 2012) endereçado a pesquisadores de língua espanhola em uma universidade pública da Argentina. Os dados analisados foram as duas versões dos resumos escritos pelos alunos antes e depois da implementação do curso. Da avaliação das produções, feita com base no sistema de Avaliatividade, a autora destaca a eficácia da abordagem PLpA para o ensino de gêneros científicos para alunos de Inglês como Língua Estrangeira.

Seguindo essa mesma linha do letramento acadêmico, estabelecendo relações entre os estratos léxico-gramatical, semântico-discursivo e contextual, em certa medida, contemplados nos artigos anteriores, Lisiane B. M. G. Silva (Rede Municipal de Ensino), Débora P. Haag (Rede Privada de Ensino), Sulany S. Santos (UEPG) e Lucia Rottava (UFRGS), no artigo "O texto e a linguagem em perspectiva: as investigações científicas sob a luz da LSF na Organon, Porto Alegre, v. 36, n. 71, p. 5-15, jan./jun. 2021. 
Universidade Federal do Rio Grande do Sul (UFRGS)", apresentam um panorama dos estudos no âmbito da graduação, da pós-graduação e de publicações que contribuíram "para a compreensão teórico-metodológica da escrita e/ou reescrita", a partir da análise de um corpus constituído de textos produzidos por alunos ingressantes no curso de Letras da UFRGS.

Com foco na multimodalidade, Dayse Garcia Miranda (UFOP), no artigo "Reflexões sobre livro didático adaptado em Libras: sob a ótica da LSF à noção de multimodalidade", traz à discussão a problemática relacionada à adaptação dos livros didáticos de língua portuguesa para o ensino de Libras. O dado da pesquisa é um livro digital de português, em Libras, acompanhado por CD que oferece aos alunos surdos vídeos. O conteúdo dessa mídia digital apresenta, ao final de cada frase, um ícone que o leva a uma tela com um intérprete de Libras. Da análise, a autora conclui que as limitações do material advêm de uma crença de que a simples transposição de uma língua para outra já constitui um material bilíngue e da necessidade de uma compreensão mais clara do que envolve a educação bilíngue.

A multimodalidade voltada para o ensino também é focalizada no artigo "Leitura de texto imagético em língua inglesa e a construção de significados a partir de recursos semióticos", de Sheilla Andrade de Souza (IFMG-Ipatinga). Com o objetivo de apresentar uma proposta de atividade de leitura com o texto imagético, a autora articula conceitos da LSF a alguns termos essenciais da Semiótica Social de Kress e van Leeuwen (2006), dentre os quais a noção de signo discutida por Natividade e Pimenta (2009) e o conceito de "interesse" abordado por Kress (2010). Para a geração do corpus, a autora implementou uma pesquisa participante e desenvolveu uma atividade que consistiu na leitura de um texto imagético, seguida das questões de compreensão textual, cujas respostas foram analisadas com base na Semiótica Social. A autora conclui que os modos de significação, dentre os quais o multimodal, precisam ser levados para a sala de aula durante as práticas de leitura de textos.

Para compreender imagens em uma unidade de livro didático de língua inglesa, Sulany Silveira dos Santos (UEPG) e Carla Murialdo (UEPG), no artigo "Representações de escola em um livro didático de inglês à luz da Gramática do Design Visual”, analisam imagens de sala de aula presentes na página de abertura de uma unidade do livro que representam contextos de sala de aula de diferentes países. Para compreender as representações de escola nessas imagens, as autoras recorrem às metafunções interativa e composicional e verificam que tais imagens revelam uma visão estereotipada do negro no livro didático.

No âmbito de pesquisas que estabelecem interlocuções teóricas, cinco artigos articulam princípios da LSF com outras abordagens, como Análise de Discurso Crítica, 
Linguística Aplicada, Psicologia Cognitiva e Histórico-Cultural e Dialogismo, indicando a potencialidade da LSF no diálogo com outras teorias.

Maria Aparecida Resende Ottoni (UFU) e Bianca Mara Guedes de Souza (UFU), no artigo "As avaliações sobre mulheres e aborto na Folha de São Paulo: uma análise discursiva crítica", articulam a LSF, em particular no estrato semântico-discursivo com foco no sistema da Avaliatividade (MARTIN; WHITE, 2005), e a Análise de Discurso Crítica (ADC) (CHOULIARAKI; FAIRCLOUGH, 1999; FAIRCLOUGH, 2001; 2010). Em seu estudo, as autoras investigam as identificações discursivas sobre o aborto e as mulheres que abortaram construídas na prática jornalística, a partir da análise de uma reportagem publicada no jornal online Folha de São Paulo, que tinha entre suas fontes jornalísticas mulheres que abortaram. Como resultados relativos às identificações do aborto e das mulheres que abortaram construídas no texto sob análise, foram verificados padrões de enquadramento do tema e dos atores sociais mulheres, observáveis a partir das escolhas léxico-gramaticais utilizadas, que refletem a enormidade do problema social que é o abortamento legal.

Também articulando a LSF com a Análise Crítica do Discurso, Martha Julia Martins (UFRR) e Viviane Heberle (UFSC), no artigo “Amazon endangered: investigating Chico Mendes's case in online newspapers", fazem uma análise das escolhas léxico-gramaticais feitas pelos autores de artigos jornalísticos para se referirem a Chico Mendes. Os resultados sugerem que o protagonista Chico Mendes é retratado como herói nacional em todos os processos analisados linguisticamente - Materiais, Relacionais e Verbais.

Voltado à formação de professores, o artigo "A formação de professores na cidade de Catalão-GO: uma análise semântico-discursiva segundo o subsistema de Atitude”. de Ingride Chagas Gomes (UFCAT), Lucas Eduardo Marques Santos (UFCAT) e Fabíola Aparecida Sartin Dutra Parreira Almeida (UFCAT), articula a LSF e a Linguística Aplicada. Como recorte de uma pesquisa em andamento, o objetivo é compreender, a partir da análise de recursos linguísticos do estrato semântico-discursivo, em particular do subsistema de Atitude do sistema de Avaliatividade, o discurso construído por professores da rede pública que atuam em área distinta à sua formação inicial. Os resultados mostram as impressões desses professores sobre as disciplinas em que atuam.

Outro estudo em que a LSF estabelece interlocuções com outras teorias é o de Graziela Fachim, doutoranda na UFSM, intitulado “Amor e adolescência nos dias de hoje: uma análise sistêmico-funcional". Em função da temática contemplada em seu estudo, a autora justifica uma reflexão com base na Psicologia Cognitiva e Histórico-Cultural e utiliza a Linguística Sistêmico-Funcional, em particular o sistema de Transitividade, para delinear os critérios de 
análise do corpus da pesquisa, constituído de relatos pessoais. A análise centra-se no papel dos jovens e na categoria a eles relacionada. Os resultados inferidos a partir dos principais processos envolvidos e do reconhecimento dos traços linguísticos presentes nos relatos revelam a complexidade temática e a indicação de outros estudos que contemplem a emoção (BEDNAREK, 2008).

Considerando o contexto escolar e estabelecendo interlocuções teóricas, o artigo de Luciane Kirchhof Ticks (UFSM) e de Patricia Streppel Hartemink (UFSM), com o título "Monologia e dialogia no discurso de uma professora de língua inglesa em um contexto escolar de EJA", analisa o discurso de uma professora de língua inglesa a fim de identificar como estão realizadas, no estrato léxico-gramatical, as ações dialógicas e monológicas por ela adotadas durante o desenvolvimento de uma aula da modalidade do Ensino de Jovens e Adultos (EJA). As autoras recorrem ao conceito de dialogismo (BAKHTIN, 1981; 1986; SCOTT; MORTIMER; AGUIAR, 2005) para depreender as ações e às metafunções da LSF para compreender como essas ações são constituídas por seus significados. Os resultados apontados pelas autoras é que as ações monológicas, realizadas por processos verbais e relacionais do sistema de Transitividade e por comandos e declarações das funções de fala, restringem a participação dos alunos. As ações dialógicas, por sua vez, dão voz aos alunos, levando-os à reflexão, por meio de processos mentais e do uso da função semântica de pergunta.

Além de brindar o leitor com uma ampla gama de artigos e reflexões que colocam em foco a produtividade da LSF, a Organon, na seção livre desta edição, oferece aos interessados em saber mais dessa teoria a "Lista de Termos da LSF em português brasileiro: transitividade". Trata-se de uma contribuição dos organizadores deste número temático conjuntamente com representantes do Grupo SAL - Sistêmica, Ambientes e Linguagens, cadastrado no CNPq, e do Grupo de Trabalho de Linguística Sistêmico-Funcional da ANPOLL (Associação Nacional de Pós-Graduação e Pesquisa em Letras e Linguística).

O número temático da Organon encerra-se com a resenha escrita por Jéssica Cantele de Freitas (UFSM) e Cristiane Salete Florek (UFSM) que reporta os estudos na obra Estudos de transitividade em Linguística Sistêmico-Funcional, organizada por Cabral e Barbara (2018). 


\section{REFERÊNCIAS}

BAKHTIN, M. Speech Genres \& Other Late Essays. Austin: University of Texas Press, 1986.

BAKHTIN, M. The Dialogical Imagination: Four Essays. Austin: University of Texas Press, 1981.

BEDNAREK, M. Emotion Talk Across Corpora. New York: Palgrave McMillan, 2008.

CABRAL, S. R. S.; BARBARA, L. (Orgs.). Estudos de transitividade em Linguística Sistêmico-Funcional. Santa Maria, RS: PPGL, 2018.

CHOULIARAKI, L.; FAIRCLOUGH, N. Discourse in Late Modernity - Rethinking Critical Discourse Analysis. Edinburgh: Edinburgh University Press, 1999.

FAIRCLOUGH, N. Critical Discourse Analysis: The Critical Study of Language. 2. ed. London: Routledge, 2010.

FAIRCLOUGH, N. Discurso e mudança social. Coordenação de tradução de Izabel Magalhães. Brasília: Editora Universidade de Brasília, 2001.

HALLIDAY, M. A. K. Language as social semiotic: The social interpretation of language and meaning. Maryland: University Park Press, 1978.

HALLIDAY, M. A. K.; MATTHIESSEN, C. Halliday's Introduction to Functional Grammar. New York: Routledge, 2014.

HALLIDAY, M.A. K.; MARTIN, J. R. Writing Science: Literacy and Discursive Power. Pittsburgh: University of Pittsburgh Press, 1993.

KRESS, G. Multimodality: a social semiotic approach to contemporary communication. London: Routledge, 2010.

KRESS, G.; van LEEUWEN, T. Reading Images: the Grammar of Visual Design. 2. ed. London; New York: Routledge, 2006.

MARTIN, J. R.; VEEL, R. (Eds). Reading Science. Critical and Functional Perspectives on Discourses of Science. London: Routledge, 1998.

MARTIN, J. R.; WHITE, P. R. R. The Language of Evaluation: Appraisal in English. London: Palgrave, 2005.

MOYANO, E. I. El lenguaje de las disciplinas y los géneros de su recontextualización escolar Una aproximación desde la lingüística sistémico-funcional. En: MOYANO, E. I. (Coord.) Aprender ciencias y humanidades: una cuestión de lectura y escritura: aportes para la construcción de un programa de inclusión social a través de la educación lingüística. Buenos Aires: Universidad Nacional de General Sarmiento, 2013. p. 31-78.

MOYANO, E. I. La enseñanza de la lectura y la escritura académicas mediante un programa a lo largo del curriculum universitario: opción teórica, didáctica y de gestión. Delta, São Paulo, v. 34, n. 1, p. 235-267, 2018. 
NATIVIDADE, C.; PIMENTA, S. A semiótica social e a multimodalidade. In: PIMENTA, S.; AZEVEDO, A.; LIMA, C. (Org.). Incursões semióticas: teoria e prática de GSF, multimodalidade, semiótica social e ACD. Rio de Janeiro: Livre Expressão, 2009. p. 21-29.

ROSE, D.; MARTIN, J. R. Learning to write, reading to learn - Genre, knowledge and pedagogy in the Sydney School. Sheffield; Bristol: Equinox, 2012.

SCOTT, P. H.; MORTIMER, E. F.; AGUIAR, O. G. The tension between authoritative and dialogic discourse: a key feature of meaning making interactions in secondary school science classrooms. Science Education, New York, v. 90, n. 7, p. 605-631, 2005.

DOI: http://dx.doi.org/10.22456/2238-8915.117001 